Title: Mentor evaluation of a year-long mentorship program: A quality improvement initiative

\author{
Authors: \\ Mary Ann van Eps RN MN \\ Nurse Educator, Staff Development \\ The Queen Elizabeth II Hospital \\ Brisbane Qld Australia \\ Marie Cooke RN PhD \\ Senior Lecturer \\ Research Centre for Clinical Practice Innovation \\ Griffith University, Brisbane, Australia \\ Debra K. Creedy RN PhD \\ Professor \\ Research Centre for Clinical Practice Innovation \\ Griffith University, Gold Coast, Australia \\ Rachel Walker RN BA BN \\ Lecturer \\ Faculty of Nursing \& Health \\ Griffith University, Brisbane, Australia
}

Please address all correspondence to:

Dr Marie Cooke

Faculty of Nursing \& Health

Griffith University

Kessels Road

Nathan, Brisbane, Q 4111

Australia

$\mathrm{Ph} 61+7+38757985$

Fax $61+7+38755431$

Email: $\underline{\text { m.cooke@mailbox.gu.edu.au }}$ 


\section{Acknowledgement}

We wish to acknowledge Ms Dianne Jones previous Director of Nursing at the Queen Elizabeth II Jubilee Hospital, whose vision led to the instigation of the peer-mentoring program in 1999. 


\title{
Mentor evaluation of a year-long mentorship program: a quality improvement initiative
}

\begin{abstract}
This paper presents twenty-three mentors' perceptions of their role in a year-long peer-mentorship program during the period $1999-2002$. The majority of mentors were clinical specialists, had bachelor degrees and over 5 years clinical experience. The mentorship program was informed by the Deming Cycle of Plan, Do, Check and Act. This quality improvement framework was used to evaluate the mentorship program from the mentors' perspective. Information was gathered through surveys, and focus group discussions. Responses were analysed to identify three themes of 'Enhancing student learning outcomes', 'Time and resources' and 'Personal and professional growth'. Mentors perceived their role as valuable in students' education and development. Despite concerns regarding adequate time and resources for an effective mentoring program, mentors acknowledged benefits to themselves in terms of personal and professional growth. Their vision and commitment to nursing was also evident in the perceived benefits of the program for the profession.
\end{abstract}

Key words: Clinical nurse education, mentorship program, mentors, student nurse, program evaluation, Deming cycle 


\section{Introduction}

Clinicians play an important role in facilitating practice-based learning for student nurses. The use of mentoring processes to facilitate learning has gained momentum in nursing since the 1980s (Andrews \& Wallis 1999 p202). Mentors are experienced and knowledgeable registered nurses who assist students in their personal and professional growth in the practice environment through workbased learning opportunities. Spouse (2001 p513) identified four main areas of the mentor role as supervision, teaching whilst engaged in expert practice activities, assessment feedback, and provision of emotional support. Clinicians, as mentors in undergraduate nurse education, advance students' integration of theory and practice. Despite the well-known importance of mentoring, few studies have reported on the evaluation of mentoring programs as a quality improvement initiative.

The mentorship program outlined in this paper was a collaboration between relevant staff of a hospital and university school of nursing. The program commenced in 1999 and was evaluated according to the Deming Cycle (Deming 1982) - a process improvement tool used extensively in industry that involves a 4 step continuous process of Plan, Do, Check, Act (PDCA).

Identifying how to improve the provision of a supportive collaborative clinical learning environment was the first step in the Deming Cycle. To establish an improvement plan, staff of the hospital and school of nursing undertook a needs assessment. Information collected at this meeting resulted in a plan to implement a mentorship program. The aims of the mentorship program were to promote the socialisation of undergraduate nurses in the profession, provide opportunities for clinicians to share their expertise with students and develop mentoring skills, make students feel welcomed, supported and valued members of the clinical environment, and contribute to the organisation's recruitment strategy. 
A shared view of mentorship was developed during a workshop with hospital administrators, educators, clinicians, academics, and informed by a review of the literature. The mentor role was seen to:

- Support mentees both in the areas of professional and clinical skill development

- Facilitate learning by immersion in clinical situations thereby integrating theoretical knowledge into nursing practice

- Guide mentees in the management of conflicting roles and responsibilities

- Work in a supportive partnership with mentees

- Guide mentees towards challenging learning experiences

- Act as a resource person

- Provide opportunities to develop reflective practice

- Coach by providing guidance in the areas of clinical practice

- Provide opportunities for mentees to become socialized into the health care team

- Utilise feedback to ensure that the mentorship process was meeting stated objectives

Twenty-three registered nurses mentored thirty-nine students during the period $1999-2002$ and quality assurance information was gathered in various ways. As the Deming Cycle is cyclical, continued improvements were made to the program following analysis of information gathered in the Act step of the process. These changes included the early identification of mentees accepted into the program, revisions of written information provided to mentees and mentors on their respective roles and expectations in relation to the program, and the inclusion of a series of information sessions for mentors about academic course content in the third year of the BN program. This paper reports on mentor perceptions about their role and effectiveness of the program gathered from information sought in the third phase (check) of the Deming cycle. 


\section{Literature Review}

The broader education literature reports consistent benefits of mentorship. In one review of 159 studies Ehrich et al (2002 p257) identified that the six most frequently cited positive outcomes for mentors were:

- collegiality/ collaboration/ networking/sharing ideas/ knowledge,

- reflection,

- professional development,

- personal satisfaction/reward/growth,

- interpersonal skill development, and

- enjoyment/ stimulation/ challenge.

The most frequently cited barrier of effective mentorship was having sufficient time to spend with mentees. Although not specifically related to mentorship programs in nursing, the findings of the review outline positive and negative perspectives of the mentor role that can be applied to the nursing context.

Although there is recent literature that examines nursing students' perceptions of mentors (Chow \& Suen 2001, Lo 2002, Watson 1999), the roles and responsibilities of mentors (Gray \& Smith 2000, Hayes \& Harrel 1994, Neary 2000, Pulsford et al 2002, Watson 2004) and the relationship between mentors and students (Andrews \& Chilton 2000, Spouse 2001, Andrews \& Roberts 2003), there are few evaluation studies of mentorship programs for student nurses from a mentor's perspective.

Interviews with twelve UK registered nurses who had mentored at least two students identified six key aspects of their role (Atkins \& Williams 1995). These categories were supporting students, facilitating learning, learning through students, managing conflicting roles and responsibilities, being supported by colleagues, and, working in partnership (Atkins \& Williams 1995 p1009). This work advances our understanding of mentors' experiences and the potential of mentoring to also contribute to the personal and professional growth of registered 
nurses. Concerns about the mentoring role related to the time needed to provide effective mentoring and conflicting responsibilities in terms of patient load and expectations of colleagues. These findings are similar to other studies that investigated mentorship during planned clinical placements (Pulsford et al 2002, Watson 2000). Furthermore, Neary (2000 p473) argued that it is "increasingly unrealistic to expect mentorship and student assessment of clinical competence to be just another activity to be tagged on to already overburdened staff requirements".

Some nurses reported aspects of the mentoring role as stressful. Watson (2000) surveyed nurses $(n=231)$ from twenty clinical areas in the UK, which represented a response rate of $44.6 \%$. Overall, respondents reported more negative experiences than positive. For example, mentors reported being inadequately prepared, time with students conflicted with patient care, and they had insufficient time to devote to students. It was argued that increasing staffing levels would improve mentoring quality and enable mentors to spend more time with students (Watson 2000). Given the adequate but low response rate in this study, it could also be that the views of respondents differed from non-respondents who may have been more satisfied with the role. Although the majority of respondents were experienced mentors, this role was enacted only during planned clinical placements and with different students on each occasion. The arrangement of supporting different students during each placement period may have contributed to role dissatisfaction.

The extent to which mentors are assisted to develop mentoring skills is not often discussed in the literature. The motivations of UK registered nurses to enhance their mentorship skills were investigated through one survey of participants ( $\mathrm{n}=$ 127, response rate 90.6\%) in a mentor preparation course (Watson 2004). The majority of participants were experienced clinicians (mean $=9.71$ years of experience, SD 8.98). The two highest motivators for undertaking the course were professional development and wanting to learn how to teach students. The 
majority of respondents $(75 \%)$ had already been involved in mentoring students in some capacity and valued their previous experiences as mentors, but wanted continuing professional education on teaching and learning strategies. Another study on the needs of UK clinicians who mentor students identified that although more than half of respondents (117 out of 198) had more than 5 years of experience as a mentor, $21 \%$ had never received a mentor update session (Pulsford et al 2002).

One of the few published Australian studies on mentoring examined the experiences of 65 registered nurse (RN) mentors in a program involving second year nursing students during a two to four week planned placement (Lo \& Brown 2000). The survey sought information on a mentor guidebook provided in the program, aspects of the mentor role, perceptions of students' clinical performance, as well as positive and negative aspects of the program. Mentors perceived that the strengths of the program for students were being befriended by a supportive colleague, promoting a realistic view of nursing, a valuable use of practicum time, and better integration into the hospital environment (Lo \& Brown 2000 p12).

Benefits for RN mentors included satisfaction from contributing to student learning, clinical skill development and confidence; developing skills and knowledge of mentoring, improved job satisfaction, promoting and improving the professional image of nursing and, a desire to share past experiences (Lo \& Brown 2000 p12). Concerns identified by the RN mentors related to the time needed to adequately mentor students. Similar to the findings of previous studies, respondents suggested that mentors should be allocated a lighter patient caseload to allow more time to spend with mentees. Other reported factors that can assist mentors related to management support, partnership with the Higher Education Institution, opportunities to learn the necessary documentation (particularly if assessment was required), appropriate use of placements, students' motivation, and extra pay (Pulsford et al 2002 p444). 
Clearly, mentorship programs are perceived as valuable in the practice-based education of nurses however previous studies have evaluated programs that involve mentoring only during planned clinical placements and focus on roles and responsibilities rather than mentor evaluations of the benefits of the program itself within a quality improvement framework. The majority of recent research has emanated from the United Kingdom with very few studies from other practice contexts. The present study considers mentors' perceptions of a program that was organized and planned to meet students' practice-based learning needs throughout their final year of study. As well, the paper contributes to the dissemination of findings from quality improvement initiatives that are not often reported. Disseminating the effectiveness of quality initiatives in relation to management processes to improve clinical practice is important (Bloor 1999).

\section{"Check" evaluation process}

The third phase of the Deming cycle requires that information is gathered to determine if the instigated plan has been effective. Information about the program from mentors' perspectives was routinely collected from focus group interviews facilitated by the Nurse Educator (Staff Development) twice a year as well as anonymous open-ended questionnaires administered once a year at the completion of each year-long program. Evaluations of continuing professional activities are standard practice in the participating organization. Names of respondents are not required and outcomes of quality assurance activities are routinely considered by the nursing executive.

The questionnaire was formulated from a review of the literature and addressed the aims of the program. Questions focused on perceived strengths and weaknesses of the mentoring program, adequacy of mechanisms to support the mentoring role, and personal and professional benefits of the program for 
mentors. Face and content validity were improved through the use of a reference group that included nurse educators, registered nurses and academics who reviewed the questionnaire. Minor adjustments to the wording and structure of some questions to enhance clarity were recommended and undertaken. The evaluation data was compiled into an annual program report and considered by the hospital executive.

Anonymized data for the period 1999-2002 were analyzed for the purposes of the present paper. Data included mentors' responses to open-ended questions and transcripts of focus group interviews which were classified into specific themes. This was achieved by analyzing the content of mentor responses, clustering similar data and assigning them to a theme that described the central meaning of the clustered data. Three themes emerged: 'Enhancing student learning outcomes', 'Time and resources' and 'Personal and professional growth'.

\section{Mentor characteristics}

Twenty-three mentors were involved in the program during the period 1999 2002. Table 1 shows the characteristics of the registered nurses involved in the mentorship program. Registered Nurses agreed to be a mentor for a final year student for a period of one year. Some participants mentored other students in subsequent years. All mentors were experienced Level 2 or 3 registered nurses, the majority ( $n=22$ ) had over five years clinical experience, and one had four years. Mentors worked in a range of clinical areas including, intensive care, emergency, surgical, medical, rehabilitation, operating suites, and orthopaedics. In some cases two mentors work together to support a student, if they were new to the role or worked part-time.

Insert Table 1 about here. 
Initial preparation and on-going professional development for the mentor role included a number of strategies. All mentors participated in a State Government Health Department sponsored preceptorship program. The hospital also supported a number of mentors to complete a clinical teaching subject offered by the university. Discussion groups facilitated by the Nurse Educator, Staff Development were held each year to orientate staff to the role and thereafter as a support mechanism while the program was offered. All participants were given written guidelines and the nurse educator maintained contact to assess needs and provide support. A number of mentors also taught the student cohort at the university in the nursing practice laboratory as part of the on-campus program. Other resources included clinical teaching workshops provided by the university and written materials on $\mathrm{BN}$ course content.

\section{Mentor Evaluations}

\section{Enhancing student learning outcomes}

Mentors identified that the program was valuable in providing students with practice based learning opportunities. The major sub-themes identified by mentors included 'The doing of nursing', 'The thinking of nursing and 'Being a nurse'. Table 2 provides examples of mentor responses within each of these sub-themes.

Insert Table 2 about here

Mentors evaluated the program positively in terms of the benefits to student learning and their role in facilitating this. Interestingly, mentor responses falling in the 'Being a nurse' sub-theme were perceived as a major benefit of the program. This finding might reflect the fact that the Year 3 students involved in the program would be graduating and working as registered nurses in the near future and as such would become colleagues of the mentors. 


\section{Time and resources}

Responses from participants identified concerns regarding the time and energy needed to be involved in the program. This finding is consistent with other Australian studies (Lo \& Brown 2000, Pulsford et al 2002). Many felt conflicting responsibilities in terms of patient care needs and student learning needs. Many also acknowledged that they used their own time to support and guide students. This support may have included providing written references for mentees and reviewing draft job applications. Examples of mentor concerns included:

Have found it quite difficult at times because of my level 2 responsibilities to spend time with the mentee as a lot of my time in a shift is taken up by organizational needs eg running a shift, meetings etc

I think it would be better if mentors had allocated time within the hospital budget to interview and consult with mentees instead of in our own time.

Lack of time to give adequate attention, as patient load/care still needs to be attended to.

Despite their concerns all mentors were satisfied with the aims and structure of the program and the resources used to support and develop their role and responsibilities. Mentors gained satisfaction from the enthusiasm of students and being acknowledged as clinical experts, but reported inadequate time to spend with mentees. Participants also felt valued by students for making a real contribution to their learning but mentorship was provided in addition to a full clinical load.

\section{Personal and professional growth}


As well as the obvious perceived benefits for students in the program, mentors also reported worthwhile advantages for them. This finding is also consistent with the literature (Atkins \& Williams 1995, Watson 2004). Participants reported that mentorship conveyed realistic expectations of the role of the registered nurse and facilitated learning opportunities for students. Ultimately, these learning processes for undergraduate nursing students were seen to contribute to the betterment of the profession. Mentors reported:

The tips from experienced staff enhances students' abilities to put together theory and practice faster for the patient's benefit

Students who have realistic expectations of the profession are less likely to leave because they are disillusioned, aren't coping, afraid of unexpected events... and they are more able to work in a team

Being a mentor also prompted reflection on the registered nurses' own practice and provided additional learning opportunities. These benefits are illustrated by the following mentor responses:

It makes you question your own practice and why we do things the way we do I enjoy working with mentees, a lot of their ideas are quite refreshing and sometimes challenging

Mentoring emphasizes the importance of encouraging collaborative practice between educational institutions and the practice area

Not only did mentors envisage benefits for themselves but also long term benefits for students, patients, and the nursing profession in general. The experience of contributing to the development of confident, competent 
registered nurses was satisfying for the majority of participants and evidenced by their willingness to continue to sponsor students over an extended period of time.

\section{Conclusion}

The mentor evaluations gathered as part of the Deming cycle of quality improvement identified that mentorship is a valuable experience for the registered nurses involved. Mentors perceived that their role provided opportunities for planned practice-based learning for students in their transition to becoming a registered nurse. Mentors in nurse education often perceive that they offer educational, emotional and managerial support to students and attach importance to their role in teaching and supporting students' learning needs (Neary 2000).

Although there were concerns regarding time and resources necessary to provide an effective mentorship program, the mentors clearly acknowledged benefits in terms of their personal and professional growth. Their vision and commitment to nursing was also evident in the perceived benefits of the program for the profession in general. In line with recommendations from the literature, the present mentoring program reflects "best practice". In particular, mentors were prepared for their role, had three complementary course offerings to choose from and received written guidelines. Furthermore, a nurse educator concerned with staff development provided ongoing support throughout the year-long program. The continuity of the mentor-student relationship over time resulted in mentors reporting sustained satisfaction with their role and a willingness to be a mentor for several years. There was tacit support and interest from management in regards to the success and quality of the program. Finally, the program represents a close partnership with the Higher Education Institution. 
Although the number of mentors involved in this initiative was not large the findings suggest that the development of similar mentorship programs would be worthwhile in preparing final year nursing students for the workplace. The program represents a long-term investment by the organization for quality clinical learning. There is a need for such programs to be systematically evaluated and the findings incorporated into a quality cycle of improvement. The success of the present quality improvement initiative has ensured its continued implementation. 


\section{References}

Andrews M, Wallis M 1999 Mentorship in nursing: a literature review. Journal of Advanced Nursing 29(1): 201-207

Andrews M, Chilton F 2000 Student and mentor perceptions of mentoring effectiveness. Nurse Education Today 20: 555-562

Andrews N, Roberts D 2003 Supporting student nurses learning in and through clinical practice: the role of the clinical guide. Nurse Education Today 23: 474 481

Atkins S, Williams A 1995 Registered nurses' experiences of mentoring undergraduate nursing students. Journal of Advanced Nursing 21: 1006-1015

Bloor G 1999 Organisational culture, organisational learning and total quality management: A literature review and synthesis. Australian Health Review 22(3): $162-179$

Chow F, Suen L 2001 Clinical staff as mentors in pre-registration undergraduate nursing education: students' perceptions of the mentor's roles and responsibilities. Nurse Education Today 21: 350-358

Deming W E 1982 Quality, productivity and competitive position. Massachusetts Institute of Technology, Cambridge.

Ehrich L, Tennent L, Hansford B 2002 A review of mentoring in education: Some lessons for nursing. Contemporary Nurse 12: 253-264 
Gray M, Smith L 2000 The qualities of an effective mentor from the student nurse's perspective: findings from a longitudinal qualitative study. Journal of Advanced Nursing 32 (6): 1542-1549

Hayes E, Harrel C 1994 On being a mentor to nurse practitioner students: The preceptor-student relationship. Nurse Practice Forum 54(4): 220 - 226

Lo R, Brown R 2000 A clinical teaching project: Evaluation of the mentorarranged clinical practice by RN mentors. Collegian 7(4): 8-10, 12, 13, 42

Lo R 2002 Evaluation of a mentor-arranged clinical practice placement. Collegian 9(2): $27-32$

Neary M 2000 Supporting students' learning and professional development through the process of continuous assessment and mentorship. Nurse Education Today 20: 463-474

Pulsford D, Boit K, Owen S 2002 Are mentors ready to make a difference? A survey of mentors' attitudes towards nurse education. Nurse Education Today 22: $439-446$

Spouse J 2001 Bridging theory and practice in the supervisory relationship: a sociocultural perspective. Journal of Advanced Nursing 33(4): 51 -522

Watson N 1999 Mentoring today - the students' views. An investigative case study of pre-registration nursing students' experiences and perceptions of mentoring in one theory/practice module of the Common Foundation Programme on a Project 2000 course. Journal of Advanced Nursing 29(1): $254-262$

Watson S 2000 The support that mentors receive in the clinical setting. Nurse Education Today 20: 585-592 
Watson S 2004 Mentor preparation: reasons for undertaking the course and expectations of the candidates. Nurse Education Today 24: 30-40 
Table 1: Characteristics of mentors involved in mentorship program

\begin{tabular}{|l|l|}
\hline Characteristics & $\mathrm{n}$ \\
\hline $\begin{array}{l}\text { Male } \\
\text { Female }\end{array}$ & 2 \\
\hline $\begin{array}{l}\text { Level of appointment } \\
\text { Level 2 (Clinical Nurse) } \\
\text { Level 3 (Nurse Manager/Consultant) }\end{array}$ & 21 \\
\hline $\begin{array}{l}\text { Highest Qualification } \\
\text { Certificate }\end{array}$ & 18 \\
Diploma & 5 \\
Bachelor degree & 1 \\
Masters degree & 16 \\
\hline $\begin{array}{l}\text { Years of experience } \\
\text { Less than } 5 \text { years } \\
\text { More than } 5 \text { years }\end{array}$ & 1 \\
\hline $\begin{array}{l}\text { Involvement in mentorship program } \\
\text { One year } \\
\text { Two years } \\
\text { Three years }\end{array}$ & 1 \\
\hline
\end{tabular}


Table 2: Mentor responses regarding enhancing student learning outcomes.

\begin{tabular}{|c|c|c|}
\hline 'The doing of nursing' & 'The thinking of nursing' & 'Being a nurse' \\
\hline $\begin{array}{l}\text { - } \text { Practical skills } \\
\text { - } \text { Basic care } \\
\text { - } \text { Hands on skills } \\
\text { administration } \\
\text { - Removing drains } \\
\text { - Inserting urinary } \\
\text { catheters } \\
\text { - IV therapy and } \\
\text { drugs } \\
\text { - Wound } \\
\text { management }\end{array}$ & $\begin{array}{l}\text { - } \begin{array}{l}\text { Time management } \\
\text { - work allocation, } \\
\text { prioritizing } \\
\text { activities }\end{array} \\
\text { - } \begin{array}{l}\text { Bridging theory- } \\
\text { practice gap }\end{array} \\
\text { - Discharge } \\
\text { planning and } \\
\text { community } \\
\text { resources } \\
\text { - Problem solving } \\
\text { - Comprehensive } \\
\text { approach to care } \\
\text { - Reality of putting } \\
\text { theory into } \\
\text { practice }\end{array}$ & $\begin{array}{l}\text { - Reintroduce the } \\
\text { ethic and } \\
\text { commitment to the } \\
\text { profession of } \\
\text { nursing } \\
\text { - Make the } \\
\text { transition from } \\
\text { student to an } \\
\text { employee a bit } \\
\text { less stressful and } \\
\text { traumatic } \\
\text { - Culture and } \\
\text { routine of the unit } \\
\text { - Career planning } \\
\text { Allows graduates } \\
\text { to be confident } \\
\text { that they can fit } \\
\text { into ward routines } \\
\text { etc. }\end{array}$ \\
\hline
\end{tabular}

